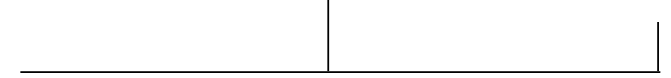

Rev. Latinoam. Psicopat. Fund., São Paulo, v. 11, n. 2, p. 315-328, junho 2008

\title{
A correspondência entre Juliano Moreira e Hermelino Lopes Rodrigues: as relações de um mestre e seu discípulo na constituição do campo psiquiátrico em Minas Gerais
}

Renato Diniz Silveira

\begin{abstract}
A partir da experiência de Hermelino Lopes Rodrigues na consolidação do campo psiquiátrico em Minas Gerais, na década de 1920, este artigo tem como objetivo descrever e analisar as principais dificuldades enfrentadas por Lopes Rodrigues nas implantações de seu projeto assistencial como diretor do Instituto Raul Soares. Além disso, aborda a influência de Juliano Moreira como interlocutor principal de Lopes Rodrigues, se utilizando de uma parte da correspondência entre os dois psiquiatras, $e$ demonstrando a importância que essas cartas inéditas adquirem na recomposição e análise dos fatos históricos estudados.
\end{abstract}

Palavras-chave: História da psiquiatria, ensino psiquiátrico, Hermelino Lopes Rodrigues 
Na segunda metade do século XIX, a inauguração do primeiro Hospício do Brasil (Hospício de Pedro II, em 1852) marca o esforço dos médicos em tomar para si o tratamento dos insanos mentais, em detrimento dos cuidados dispensados pela Santa Casa de Misericórdia. Com a Proclamação da República, o Hospício de Pedro II se torna o Hospício Nacional de Alienados. A partir de 1903, um novo diretor, o médico baiano Juliano Moreira (1873-1933), modificaria a assistência desse estabelecimento, introduzindo práticas que refletiam um profundo conhecimento do campo psiquiátrico mundial adquirido por Moreira por meio de suas leituras e viagens à Europa. É comum atribuir a Juliano a "paternidade" da psiquiatria no Brasil. Sobre isso, nos diz Oda (2003):

Se cada especialidade profissional moderna costuma escolher seus pais fundadores entre aqueles que sintetizam as melhores qualidades, os atributos desejáveis ou exemplares no julgamento de seus sucessores, ou ainda entre os que se destacaram pela excepcionalidade, então, a biografia de Juliano Moreira faz compreender tal eleição. (p. 304)

Embora não se tornasse professor da Faculdade de Medicina do Rio de Janeiro, Juliano Moreira se constituiu, a partir de seu trabalho, em um importante transmissor dos conhecimentos científicos psiquiátricos de inspiração alemã, influenciando uma série de jovens psiquiatras que iriam disseminar esses conhecimentos em vários estados brasileiros. As contingências propiciaram um ensino prático, onde Juliano Moreira fazia com que seus conhecimentos pudessem ser diretamente observados pelos jovens alunos que freqüentavam o Hospício Nacional nas primeiras décadas do século XX. Um desses discípulos, o baiano Hermelino Lopes Rodrigues, se tornaria o primeiro (e único) professor catedrático de Clínica Psiquiátrica na capital de Minas Gerais.

Nesse sentido, este artigo tem como objetivo apresentar e analisar as influências que Juliano Moreira estabeleceu no trabalho de Lopes Ro- 
drigues, principalmente por meio da correspondência travada entre o discípulo e seu mestre. A partir de 1929, Lopes Rodrigues seria nomeado diretor do Instituto Raul Soares, primeiro estabelecimento dedicado ao tratamento de insanos mentais em Belo Horizonte. Suas dificuldades no cargo foram inúmeras, pois apesar do apoio de Moreira, ele não fez alianças em Minas Gerais, conforme veremos.

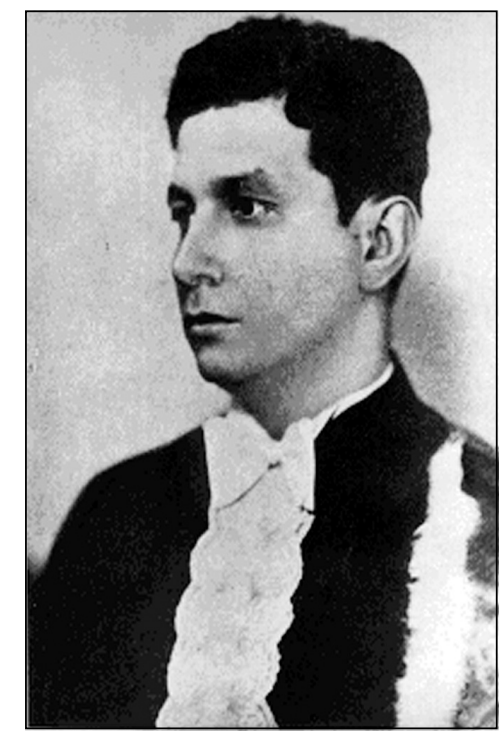

FIGURA 1

Hermelino Lopes Rodrigues (1898-1971)

Fonte: Acervo do Centro de Memória do Instituto Raul Soares

Hermelino Lopes Rodrigues nasceu em 1898, em Barra do Rio Grande, na Bahia, e faleceu em 6 de abril de 1971. Após terminar seu bacharelado em Ciências e Letras pelo Gymnasio da Bahia, matriculou-se na Faculdade de Medicina da Bahia em 1916, aos 18 anos. Em 1919, estando no governo do Estado o então senador Antonio Moriz Ferrão de Aragão, este o nomeou para o cargo de interno efetivo do Hospício São João de Deus, onde ingressou nos estudos de psiquiatria: “... uma apreciação inicial vê na preferência do jovem estudante o gosto pela psiquiatria que superou desde cedo as vantagens que lhe daria na vida prática a preferência pela cirurgia" (Os Consagrados..., 1929, p. 12).

Em 1920, Lopes Rodrigues se transfere da Faculdade de Medicina da Bahia para a Faculdade de Medicina do Rio de Janeiro, onde irá cursar o quinto ano. 
É lá que será aluno de Henrique Roxo (1877-1969) e discípulo de Juliano Moreira, se dividindo entre o ambiente acadêmico e o Hospital Nacional. A influência de Moreira marcaria Lopes Rodrigues que, em 1925, se tornaria Professor Livre Docente de Clínica Psiquiátrica da Faculdade de Medicina da Universidade do Brasil, no Rio de Janeiro, por concurso. Sua tese de concurso foi sobre Demencia Paranoide, eschyzophrenias e para-eschyzofrenias. Em 1926, por sugestão de Henrique Roxo e Juliano Moreira, Lopes Rodrigues faz concurso para Professor Catedrático de Psiquiatria na Faculdade de Belo Horizonte, em Minas Gerais. Sua tese obrigatória foi um estudo sobre Ethio-patogenia da Demencia Precoce e a tese voluntária o Estudo Clinico das Eschyzophrenias. Ele estava totalmente interessado no grande debate científico da época: a substituição do conceito kraepeliniano de Demência Precoce pelas contribuições do suíço Eugen Bleuler, e seu conceito acerca da Esquizofrenia.

Aprovado com louvor no concurso mineiro, logo iniciou a correspondência com seu mestre, Juliano Moreira, contando detalhes dos primeiros tempos em Minas Gerais. Moreira era uma espécie de "bússola" para Lopes Rodrigues no terreno mineiro, e parecia ainda muito ligado ao seu mestre, conforme suas primeiras cartas:

Encontrando, em Minas, um meio de homens profundamente cultos, respirei, desde o primeiro momento, um ar de dignidade compatível com as aspirações do meu destino. Minas é uma terra de tradição, como convém a um temperamento afeito ao culto das tradições. Essa gente, daqui, reflexiva e cauta, terra de homens austeros, instruídos e veneráveis, só não quis ver o dilatado da minha escassez, para se demorar na bondade de transfigurá-la em méritos, fazendo-me professor. Minhas apreensões, no meu primeiro concurso, para Docente-Livre ai, no Rio, foram maiores; talvez o fato de ter sido a primeira batalha da minha vida, senão a resistência silenciosa ao que o Mestre sempre me aconselhou contra os que se incomodam mais com o êxito alheio do que com os seus próprios insucessos. Como terá ecoado, aí, a notícia do meu concurso? Lamento o incômodo involuntário que mais este passo do meu destino estará a infligir aos que não se conformam com os passos do destino dos outros.

Em breve, estaremos juntos e muito lhe terei a falar da grande impressão que me causou o saber dos mineiros, em cujo seio se casam autênticos humanistas a homens de grande compleição moral. É uma nobre cidade, de latinistas austeros, beletristas sóbrios e homens de serões prolongados, à sombra de camilianas, em meditados folheios. (Lopes Rodrigues, apud Pires, 1959, p. 15; grifos nossos)

Não obstante os proclamados elogios aos mineiros, Lopes Rodrigues continuou no Rio de Janeiro com seu mestre Juliano Moreira, comparecendo à capital mineira apenas para dar as aulas inaugurais de Clínica Psiquiátrica. Depois, 
voltava sempre para a companhia de Moreira, até 1929, quando é empossado diretor do Instituto Raul Soares, em Belo Horizonte. Nessa época, as condições assistenciais aos doentes mentais em Minas Gerais estavam caóticas. O único estabelecimento que se prestava a atender pacientes psiquiátricos na capital era o Instituto Raul Soares, órgão submetido à Secretaria de Segurança Pública, que encaminhava para internação obrigatória todo tipo de paciente que, por algum motivo, perturbasse a paz da cidade de Belo Horizonte.

Desta forma, superlotado, o Instituto Raul Soares havia se transformado em um depósito de pacientes, apenas quatro anos depois de ter sido inaugurado como um dos locais mais modernos de tratamento para doentes mentais. Os internados viviam amarrados por manquitos (tiras) de couro, cordas, correias, argolas, lonas e coleiras: "... os braços livres que restavam, fora dos manquitos célebres, eram para atirar montões de fezes pelas paredes, que iam até o teto" (Pires, 1959, p. 39).

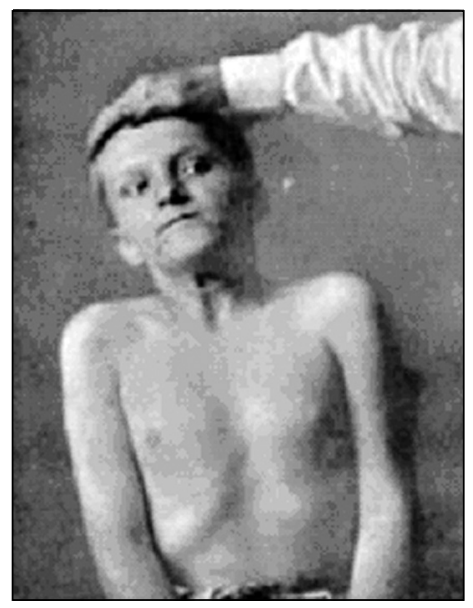

FIGURA 2

Menor acorrentado que vivia em meio aos outros pacientes.

A foto tem como objetivo mostrar a marca de tortura no pescoço

Fonte: Acervo do Centro de Memória do Instituto Raul Soares/FHEMIG.

Os gritos e o mau cheiro invadiam os cubículos abarrotados, além disso, os instrumentos de repressão, visando o controle da disciplina, eram comuns, os doentes eram sistematicamente expostos à violência física. Logo no início de 1929, o falecimento do diretor do Instituto Raul Soares, Alexandre Drummond, 
foi o fato que precipitou a decisão do presidente do Estado de Minas Gerais, Antônio Carlos Ribeiro de Andrada, em nomear um novo diretor.

Andrada buscou na Faculdade de Medicina da Universidade de Minas Gerais o responsável pela cátedra de Clínica Psiquiátrica, Hermelino Lopes Rodrigues, professor desde 1926 e que contava com trinta e um anos. Aos olhos do Presidente, Rodrigues parecia reunir condições para mudar o Instituto Raul Soares, pois além de professor universitário, ele era discípulo do afamado Juliano Moreira, reconhecido já naquela época por sua capacidade intelectual e gerencial à frente do Hospital Nacional, no Rio de Janeiro. Assim seria narrado, trinta anos depois (1959), o dia da posse de Lopes Rodrigues, nas palavras de Francisco de Sá Pires, seu futuro discípulo, que acompanhou pessoalmente os eventos daquela manhã:

No dia em que Lopes Rodrigues tomou posse do cargo de Diretor do Instituto Raul Soares, cinco minutos após a cerimônia de sua investidura, tranqüilo e sem articular uma só palavra, com fisionomia serena de quem levava na alma uma decisão resoluta, encaminhou-se para o interior do Hospital, em direção aos Pavilhões, onde os doentes jaziam encarcerados. (...) Contemplou aquele quadro e convocou imediatamente a alguns funcionários do estabelecimento, aos quais ordenou, com voz firme e pausada, que retirassem naquele mesmo minuto, todas as trancas ou derrubassem todas as portas. (...) começou a libertar os loucos dos cubículos e a retirar dos seus pulsos, dos seus braços e dos seus pés, e muitos deles com as próprias mãos, os aparelhos de suplício. Alguns loucos, ao ganharem a liberdade, saíam correndo pelos corredores, como feras enjauladas às quais se houvesse abertos as portas das jaulas. (Pires, 1959, p. 39-40)

Os funcionários do Instituto Raul Soares ficaram extremamente assustados com a ação imediata do novo diretor. Atônitos, pensaram que o novo diretor era, ele mesmo, um louco que acabava de chegar:

Os funcionários do Instituto, apavorados, moviam-se de um lado para outro, nas dependências administrativas, e bradavam: "O homem é doido!... O homem é doido!..."

"Que é que há?" - perguntavam outros.

"Está soltando as feras..."

As trancas continuavam a ranger, arrancadas às portas, e os pacientes eram desatados, um a um, diante da figura impassível do "Louco" que os libertava e os restituía ao ar e à claridade (...) dentro em pouco, a notícia corria célebre, por toda a cidade, acompanhada do epíteto alarmante: "Lopes Rodrigues é doido". (ibid., p. 40)

Os pacientes eram tratados com violência. Era comum a presença de funcionários como o “... atleta e lutador de boxe, José Batista, que gostava de exi- 
bir seus músculos de enfermeiro-chefe do Instituto Raul Soares, consagrado pela fama de derrubar qualquer doido com um murro" (ibid., p. 14).

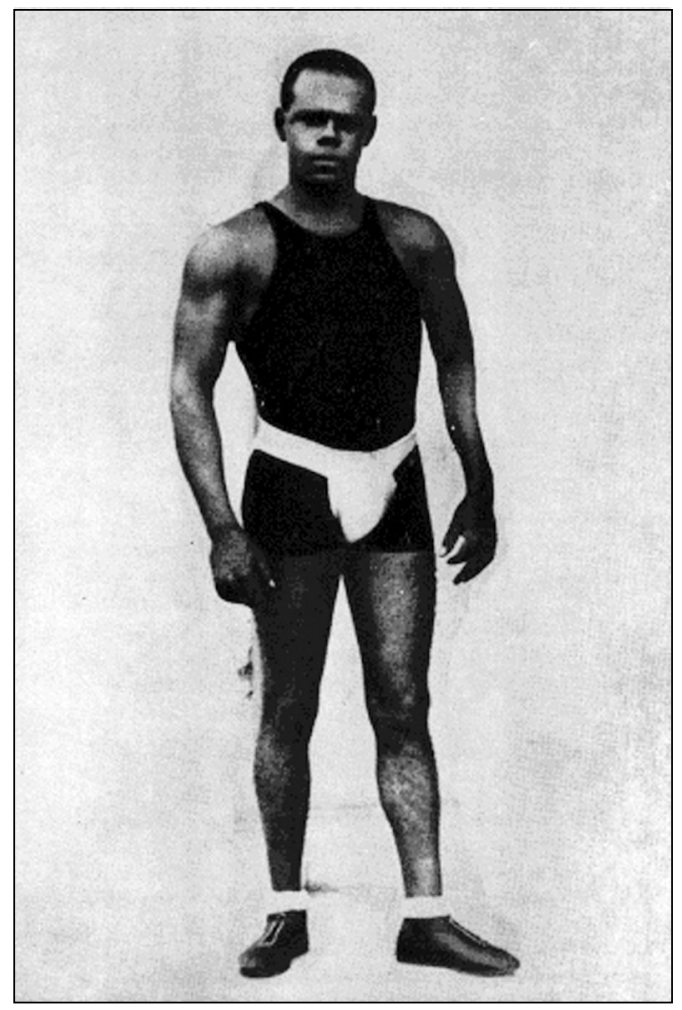

FIGURA 3

José Batista, o Enfermeiro-chefe do Instituto Raul Soares, em 1928

Fonte: Acervo do Centro de Memória do Instituto Raul Soares/FHEMIG.

Após desamarrar os pacientes e retirá-los dos quartos que funcionavam como celas, Lopes Rodrigues preconizou o "serviço aberto", onde os pacientes poderiam transitar livremente pelas dependências do Instituto. A defesa que ele fazia de um serviço sem pacientes amarrados partia da argumentação de que uma parte da agitação psicomotora dos doentes, provinha da agressividade dispensada a eles no tratamento. 
Essas mudanças, no entanto, não foram fáceis. Não obstante o apoio presidencial, Lopes Rodrigues enfrentava a resistência dos funcionários assustados com a liberdade dos pacientes. De início, foram demitidos os trabalhadores mais violentos, como o enfermeiro José Batista e muitos outros. Essas demissões e a posição firme do Diretor do Instituto Raul Soares levariam a uma grande reação da comunidade hospitalar logo no início da nova gestão.

As transformações continuaram de uma forma acelerada. Ele implantaria no Instituto, naquele ano, mudanças extremamente inovadoras para a época. Porém, antes de iniciar os tratamentos científicos, precisava livrar o Instituto da situação desumana em que se encontrava. Proibiu completamente os castigos corporais. Segundo Pires (1959), os funcionários do Instituto passaram a hostilizar o novo diretor que, cada vez mais obstinado, continuava a impedir castigos e torturas:

Havia atingido ao auge a obstinação do seu apostolado, em transformar a fisionomia do hospital que começava a dirigir, diante do vozerio motejante de toda gente: "o homem é doido..." (...) Era, além do mais, a coragem indômita de um jovem desconhecido do meio, desamparado do apoio da opinião formada, arrostando o poderio do preconceito e da rotina, enfrentando hábitos, oligarquias, interesses e conspirações. Os protestos, a grita, os abaixo-assinados, as cartas anônimas para as autoridades, pediam providências contra o novo Diretor "que era um doido, pois continuava a teimar em manter doidos soltos." (p. 47)

Não se tratava de uma "teima", mas sim de uma direção clínica. Lopes Rodrigues estava certo de que não conseguiria implantar no Instituto as inovações da época com aquela situação de tortura e repressão. Não concebia tratar pacientes acorrentados. Seu primeiro problema no Instituto não foi relacionado aos pacientes, mas aos funcionários.

O Instituto tinha quatro pavilhões e, segundo os jornais, cada um tinha um guarda, que disputavam entre si qual pavilhão era o mais silencioso. Ainda em 1928, no contexto de uma visita da imprensa ao Instituto, encontramos o seguinte trecho: "Cada pavilhão tem um guarda. O guarda é obrigado a zelar por tudo quanto existe dentro dele. Vem daí a ordem que notamos" (Instituto..., 1928, p. 1). Entendemos que a ordem não tinha um eixo clínico, mas o imperioso critério do medo e da submissão aos funcionários.

Esses, por sua vez, indignados por se submeterem a um critério que não conheciam, passaram a enfrentar o novo diretor boicotando o serviço e aumentando as dificuldades. Evidentemente, a nova situação surpreendia os próprios pacientes que, ao se verem livres das cordas e do leito, começaram a se comportar de maneira mais agitada, tentando fugir e correr. O diretor do Instituto sabia que essa era uma primeira fase da liberdade, mas não havia paciência ou confiança 
nesse tratamento por parte dos funcionários do Instituto Raul Soares. Lopes Rodrigues (1930) narra o que se passou naquele início de 1929, e de suas dificuldades para se fazer entender:

A intolerância natural de todo individuo mandado, contra quem o manda, associava-se um movimento espontâneo de recuo, por todos os distritos internos do mecanismo hospitalar que pudessem comprometer a nomeada da direção e ecoar no cenário público na mesma ordem de responsabilidades, justas ou injustas, a ela atribuíveis. Foram surpreendidos, várias vezes, empregados do estabelecimento a facilitarem a fuga de doentes de responsabilidade; outros a fornecerem a compra de bebidas alcoólicas por doentes viciados; o mecanismo burocrático descalçou na inatividade de todos os deveres da escrituração e dos arquivos; bueiros, latrinas e pias surgiam diariamente entupidos; as famílias dos pensionistas passaram a receber cartas que aconselhavam a retirada imediata de seus parentes internados no Instituto; a opinião pública taxava de insano, até pela imprensa, a um diretor que cometia o crime de dar liberdade aos doentes; as cartas anônimas penetravam os recessos do executivo governamental, em libelos acusatórios, contra a dignidade privada da diretoria. (p. 68)

Com todos os pacientes soltos, tornava-se necessário adaptar os funcionários à nova mentalidade: “... uma casa de ciência, doentes mentais livres, novos métodos de tratamento, uma clínica digna do ensino da Psiquiatria" (Pires, 1959, p. 47). Lopes Rodrigues resolveu então substituir os funcionários “... recalcitrantes e viciados, e dentro em pouco, quase toda a totalidade de funcionários ele havia substituído" (ibid.). Foram abertas todas as portas do estabelecimento, proibido o fechamento de qualquer doente nos quartos, abandonados os aparelhos de resistência e os doentes passaram para o regime novo, de liberdade sob vigilância. Foram transportados das seções fechadas para as dependências externas, conforme seleção de suas possibilidades. A principal atribuição dos novos enfermeiros passou a ser a vigilância contínua em detrimento a uma simples detenção das chaves. Mas essa lógica não era apoiada e nem acompanhada pela comunidade hospitalar, como reclama Lopes Rodrigues (1930):

As trancas das portas das seções foram substituídas por plantões permanentes, postos intermediários aos desembargos da seleção inicial, apuradora dos que se tornavam definitivamente passíveis do regime aberto e dos que, necessariamente, teriam que regredir ao interior das seções não mais trancadas, porém interceptadas pela ação de uma vigília pessoal. Não foram poucas as provações intimas da diretoria, para suportar a interpretação errônea do público que confundia um importante e científico princípio em evidência seletiva, adaptacional, com o aspecto arbitrário de um "estabelecimento anarquizado" onde os "doidos fazem o que querem". ( p. 69) 
Os movimentos que Lopes Rodrigues fez no Instituto Raul Soares repercutiram no cotidiano carioca, e fizeram com que Juliano Moreira escrevesse ao seu discípulo:

\section{Meu caro Poeta.}

Estão chegando por aqui algumas notícias sobre o seu ato revolucionário, soltando as feras do Instituto e recebendo, por isso, o batismo de louco. É que a sua reconhecida pacatez transformou, de uma hora para a outra, os hábitos de uma cidade. Vá, entretanto, com calma. Roma não se fez num dia. Nunca imaginamos que o senhor fosse encontrar as coisas que encontrou aí. Vá com prudência. Mesmo assim não se esqueça de que os doentes da mente merecem o mesmo trato dado às musas. Aceite o epíteto de louco em tão propícias condições ao seu renome no futuro. Aceite o epíteto de louco antes que lhe ponham outro pior. Todos nós devemos fazer a profilaxia da parcela de insulto que nos cabe. Agarre-se a esta e continue a soltar as "feras" com a mesma pachorra. Cada mineiro que o chamar de louco está passando um atestado triste na cultura de sua própria terra e de sua própria gente. Não creio aliás que todos os mineiros estejam de acordo; em todo caso a campanha de sua loucura já chegou até aqui. Marche para frente e não olhe para os lados. (Moreira, apud Pires, 1959, p. 68)

A resposta de Hermelino Lopes Rodrigues ao seu mestre foi imediata:

Achei muita graça em haver chegado até aí o título de doido com que acaba de ser agraciada a minha decisão, menos de enfrentar a posteridade, do que fruir, no sossego da consciência, o prêmio de ter enfrentado os homens de juízo e desalgemado os insanos e inconscientes.

Lembre-se do velho adágio: Insanus lapides, verbaque dura facit, isto é, "de doido, pedrada ou má palavra". Na impossibilidade de qualquer má palavra, o que a minha higiene verbal coíbe, estou no conceito desta gente, atirando pedras... Estou "doido varrido".

"Santo Agostinho já dizia que este mundo se ri de todos os que se não riem dele. Como, realmente, não acho do que me rir, divirto-me com o frouxo de riso, a gargalhada, o pânico desta bela cidade, a me conferir o título de louco, por ter "soltado as feras"... (Rodrigues, apud Pires, 1959, p. 81)

Lopes Rodrigues não elegeu aliados em Minas Gerais. Todas as suas dúvidas, impasses, reflexões só pareciam encontrar respaldo nas possíveis opiniões emitidas por Juliano Moreira. Essa filiação intelectual exclusiva piorava o clima de trabalho no Instituto Raul Soares. Comparava as condições do ensino psiquiátrico em Minas Gerais às condições que Moreira implantara no Hospício Nacional, criticando o cenário mineiro. Parecia querer repetir o feito de seu mestre, mas o ensino psiquiátrico deveria estar alinhado com o cotidiano do estabelecimento destinado aos doentes mentais mineiros. Não conseguia cumplicidade dos médi- 
cos e funcionários que trabalhavam no hospital que ele dirigia. Em breve escreveria uma nova carta a Juliano Moreira, desta vez enfocando suas dificuldades como professor de Psiquiatria:

Professor Juliano Moreira

Mestre e amigo.

O ensino da Psiquiatria, na Faculdade, não me tem permitido passar dos monótonos expedientes de aulas teóricas, cujo cunho meramente tribunício se disfarça no aparato simulatório do seu mais sério imperativo: um paciente apanhado a esmo, entre os internados no Instituto, teatralizando a honestidade do ensino prático, na constrangedora e burlesca ação de presença a que o submetem tais colapsos da ética. O pobre paciente sentado a uma cadeira e eu, ao lado, fazendo uma preleção. É o que se denomina, aqui, em Psiquiatria, de aula... prática. (...) A segunda tarefa, a da reforma regulamentar, depende de pôr "sábios", "bacharéis", "burocratas" e "morubixabas", dentro de artigos e parágrafos, enfrentar "trâmites legais", percorrer "canais competentes", defrontar "montanhas graníticas" e arrostar com influências, interesses e grupos. Acho muito difícil desburocratizar o Instituto e torná-lo na dignidade universitária do ensino, sob a autonomia do professor. Será o embate com feudos truculentos, matulas daltônicas e aglutinações perversas; todavia, o seu catedrático tem o dever de lutar até o fim, pela organização e pela dignidade do seu ensino e da sua cadeira. Do discípulo e amigo, Lopes Rodrigues. (Lopes Rodrigues, apud Pires, 1959, p. 99)

Na direção do Instituto Raul Soares, Lopes Rodrigues fazia de Juliano Moreira seu confidente e conselheiro. Com Moreira, ele desabafava, ria do fato de ter sido apelidado de louco, comentava as suas dificuldades. Logo depois de seu concurso (1926), escreveu imediatamente a Juliano elogiando a grande impressão que lhe havia causado o saber dos mineiros, denominando-os de "... autênticos humanistas de grande compleição moral" (Lopes Rodrigues, apud Pires, 1959 , p. 15). Já nas cartas de 1929, ao se referir às dificuldades em transformar o Instituto Raul Soares em um ambiente acadêmico, afirma que terá de enfrentar “... 'feudos truculentos', 'matulas daltônicas' e aglutinações perversas compostas também por mineiros” (ibid., p. 99). Ele está falando das dificuldades na implantação das mudanças assistenciais, mas seus maiores opositores não são os médicos do Instituto, nem os professores da Faculdade de Medicina, mas os trabalhadores, principalmente os enfermeiros e os guardas.

Lopes Rodrigues compara a situação de Belo Horizonte com a ampliada visão de clínica psiquiátrica de seu grupo carioca, e diz que na capital mineira é praticamente impossível repetir as condições de boas relações entre teoria, assis- 
tência e ensino estabelecidas por Juliano Moreira. No entanto, nas cartas ele não comenta nada sobre possíveis colegas com os quais havia trocado idéias, dividido apreensões, submetido suas idéias e planos à avaliação de outros possíveis pesquisadores.

A comparação que Lopes Rodrigues faz entre o seu trabalho e o de Juliano Moreira não leva em consideração um aspecto importante: Moreira dá ao seu trabalho de aglutinador de instituições científicas a mesma importância que dá aos seus estudos especificamente teóricos. Funda associações, promove encontros, estimula o debate científico. Além disso, se preocupa com a formação de novos pesquisadores, estabelecendo uma relação próxima com os alunos interessados no assunto. Tem interlocutores longínquos, como Émil Kraepelin, mas também faz de seus colegas interlocutores presentes. Forma uma escola e um ensino em um sentido amplo desses termos.

Seu trabalho à frente do Instituto Raul Soares terminou 18 meses após sua posse, sendo substituído após a entrada de Getúlio Vargas na Presidência da República. Apesar do sucesso das implantações assistenciais, não conseguiu fazer do Instituto um campo prático para a psiquiatria ensinada na Faculdade de Medicina da Universidade de Minas Gerais. Sem dúvida, os ensinamentos teóricos de Juliano Moreira foram fundamentais, porém Lopes Rodrigues deixou de investir em um importante fator também ensinado por Moreira a partir de sua prática: a capacidade de transmitir conhecimentos e aglutinar trabalhadores em torno da meta de melhorar as condições de tratamento dispensado aos doentes mentais.

Esta experiência de transmissão pedagógica elucidada a partir do campo da História da Psiquiatria demonstra o cuidado que precisamos dispensar aos aspectos da formação profissional. Para uma disciplina como a psiquiatria que tradicionalmente é marcada por grandes e inúmeras Reformas, é necessário frisar e incluir como conteúdo programático dos programas de graduação, pósgraduação e residências médicas uma abordagem rigorosa da História da Psiquiatria, para que os jovens médicos se apropriem dos movimentos inerentes à sua profissão.

Além disso, é preciso inscrever o discurso psiquiátrico dentro do contexto de sua contemporaneidade, procurando uma transmissão de conhecimentos que leve em consideração a realidade brasileira e suas especificidades regionais. A história do ensino de psiquiatria no Brasil teve, em Juliano Moreira, um precioso exemplo dessa iniciativa. A transmissão de conhecimentos europeus foi cuidadosamente preparada por Juliano Moreira para uma apropriação no Brasil do início do século XX, e o trabalho de Hermelino Lopes Rodrigues, apresentado nesta contribuição, demonstra a excelência desse tipo de formação. Contudo, a experiência vivida por Lopes Rodrigues ilustra também a impossibilidade de se repetir 
integralmente uma experiência bem-sucedida nas relações entre o eixo teórico e o eixo prático, principalmente quando o novo contexto não é primariamente levado em conta.

\section{Referências}

Instituto Raul Soares. Jornal Estado de Minas, Bello Horizonte, 29 mar.1928, p. 1.

ODA, A.M.G.R. A teoria da degenerescência na fundação da psiquiatria brasileira: contraposição entre Raimundo Nina Rodrigues e Juliano Moreira. Psychiatry On-line Brazil - part of The International Journal of Psychiatry, v. 6, n. 12, 2003.

Os Consagrados da Sciencia: Lopes Rodrigues e o seu primeiro decênio psychiatrico - dez annos de tirocínio a serviço exclusivamente da sciencia. Illustração Mineira, Bello Horizonte, v. 2, p. 12-14, maio/jun. 1929.

PIREs, F.S. Lopes Rodrigues o louco: homenagem dos seus discípulos. Rio de Janeiro: IBGE, 1959.

Rodrigues, H.L. Instituto Raul Soares: Primeira Memória Médico-Administrativa dos Serviços de "Assistência a Alienados". Bello Horizonte: Imprensa oficial de Minas Gerais, 1930.

\section{Resumos}

(La correspondencia entre Juliano Moreira y Hermelino Lopes Rodrigues: las relaciones de un mestre y su discípulo en la constitución del campo psiquiatrico en Minas Gerais)

A partir de l'experiencia de Hermelino Lopes Rodrigues en la consolidación del ámbito psiquiátrico en l'Estado del Minas Gerais durante la década de 1920, este artículo contempla a describir y analizar las principales dificultades encontradas por Rodrigues en las implantaciones de su proyecto como director de l'Instituto Raul Soares. Además trata de l'influencia de Juliano Moreira como el principal interlocutor de Lopes Rodrigues, si utilizando d'una parte de la correspondencia entre los dos psiquiatras, y demuestra l'importancia que estas cartas inéditas adquieren en la reconstrucción y l'análisis de los hechos históricos estudiados.

Palabra clave: Historia de la psiquiatría, educación psiquiátrica, Hermelino Lopes Rodrigues 
(La correspondance entre Juliano Moreira et Hermelino Lopes Roddrigues: les rapports d'un maître et de son disciple dans la constitution du champ psychiatrique dans l'état de Minas Gerais)

À partir de l'expérience de Hermelino Lopes Rodrigues dans la consolidation du domaine psychiatrique dans l'État du Minas Gerais au cours des années 1920, cet article vise à décrire et à analyser les principales difficultés rencontrées par Rodrigues dans les implantations de son projet à titre de directeur de l'Institut Raul Soares. En outre, il traite de l'influence de Juliano Moreira comme le principal interlocuteur de Lopes Rodrigues, utilisant une partie de la correspondance entre les deux psychiatres, et démontre l'importance que ces lettres inédites acquièrent dans la reconstruction et l'analyse des faits historiques étudiés.

Mots clés: Histoire de la psychiatrie, enseignement psychiatrique, Hermelino Lopes Rodrigues

(The correspondence between Juliano Moreira and Hermelino Lopes Rodrigues: the relations between a master and his disciple in establishing the field of psychiatry in Minas Gerais)

Based on the experience of Hermelino Lopes Rodrigues in consolidating the field of psychiatry in the State of Minas Gerais, Brazil, in the 1920s, this article describes and analyzes the main difficulties he faced in his project as director of the Raul Soares Institute. The article also discusses Juliano Moreira's influence as the main interlocutor of Lopes Rodrigues by analyzing some of the letters exchanged between the two psychiatrists. The importance that these unpublished letters have in reconstructing and analyzing the historical facts involved is also brought up.

Key words: History of Psychiatry, psychiatric education, Hermelino Lopes Rodrigues

Versão inicial recebida em maio de 2008

Versão aprovada para publicação em maio de 2008

\section{Renato Diniz Silveira}

Doutor em Educação pela Universidade Federal de Minas Gerais (Belo Horizonte, MG, Brasil); mestre em Psicologia Social pela Universidade Federal de Minas Gerais; médico psiquiatra; professor do curso de Psicologia da Pontifícia Universidade Católica de Minas Gerais PUC-Minas - Betim (Betim, MG, Brasil).

Rua Montes Claros, 1358/701 - Bairro Anchieta

30130-170 Belo Horizonte, MG, Brasil

Fone: (031) 3221-1407

e-mail: renato.22@uol.com.br 